\title{
Bibliotherapy for Mental Health
}

\author{
Jennifer Yontz-Orlando ${ }^{1}$ \\ ${ }^{1}$ Valdosta State University, Valdosta, Georgia, USA \\ Correspondence: Jennifer Yontz-Orlando, 12200 Cannon Lane, Ft. Myers, FL, 33912-1422 USA. Tel: \\ 1-239-336-9016.
}

Received: April 17, 2017

Accepted: May 18, 2017

Online Published: June 7, 2017

doi:10.5430/irhe.v2n2p67

URL: https://doi.org/10.5430/irhe.v2n2p67

\begin{abstract}
The United States is facing an epidemic of mental illness, affecting nearly 60 million Americans annually (http://www.nami.org/ ). The World Health Organization describes mental health as "a long neglected problem" and has established an action plan for 2013-2020 (http://www.who.int/mental_health/action_plan_2013/en/). One way to combat mental illness is through bibliotherapy, which is the use of written materials including fiction, nonfiction, and poetry to support emotional and psychiatric healing.

Bibliotherapy has been in existence since ancient times, but began in earnest in the United States in the 1850's during the "Great Awakening." At that time, mental illness began to be seen as a medical condition rather than a supernatural phenomenon. Since then, due to the changing nature of our institutions, interest in bibliotherapy waned until the 1950's when there was a slight resurgence in its practice. However, in the last 20 years, bibliotherapy has gained a stronghold in the United Kingdom. To relieve the stress of an overcrowded mental health system, public policy in the UK has supported the use of bibliotherapy in a variety of its institutions. There are many ways to conduct bibliotherapy, but studies show that when the process is interactive, such as in a support group setting, the results are better. Also, bibliotherapy can be conducted by many sorts of professionals, including doctors, therapists, social workers, teachers, and librarians.

Studies also show that when the bibliotherapists are trained in the best practices of bibliotherapy, results improve. Bibliotherapy is an effective, low-cost alternative for people in need of therapeutic assistance. The UK model should be studied and implemented in the United States and in other nations to help solve the mental health crisis.
\end{abstract}

Keywords: bibliotherapy, mental illness, psychotherapy, counseling

\section{Overview of our Current Mental Health Care Crisis}

Mental illness is a serious problem in the United States today. Severe mental illnesses can be classified as major depression, schizophrenia, bipolar disorder, obsessive-compulsive disorder, panic disorder, post-traumatic stress disorder, and borderline personality disorder. A study published in 2011 shows that one in four Americans will face a severe mental illness that year. That same report shows that mental illness accounts for a larger proportion of disability in developed countries than any other group of illnesses, including cancer and heart disease (Reeves, Strine, Pratt, Thompson, Ahluwalia, Dhingra, \& Safran, 2011). Unfortunately, the prevalence and incidence of severe mental illness in the United States is on the rise (Baumeister, 2012).

One of the best ways to tackle mental illness and its often-devastating effects is through education (Corrigan, 2001). According to researchers, stigma is the overreaching block when combating these diseases. Stigma is a pervasive public attitude that the mentally ill are aggressive, violent, and dangerous. This stigma also holds that treatment and rehabilitation of mental disorders are improbable or too challenging and, therefore, there is a tendency to maintain a distance from the mentally ill and reject them. This defeatist attitude trickles down to the patients themselves and may keep many sufferers from seeking treatment (Wig, 1997).

It is important to educate the populace on the actual effects of mental illness to dispel many false assumptions. Most often, with proper diagnosis, treatment, social support, and the correct information, the mentally ill can lead productive and fulfilling lives (Corrigan, 2001). 
Surveys have shown that mental health patients want education, particularly in the areas of "information on the illness, medications and side effects, problem-solving strategies, and understanding the mental health system" (Fanner \& Urquhart, 2008).

\section{What Is Bibliotherapy?}

In the last 60 years, a term used in professional mental health circles has circulated called "bibliotherapy." This term is sometimes used interchangeably with "reading therapy." This modality is a supportive psychotherapeutic practice in which patients and their families are given selected material to read including self-help manuals, e-learning programs, and fiction or poetry that relates to the patients' mental health concerns. This may include follow-up professional contact, including phone contact (Fanner \& Urquhart, 2008).

Studies have shown that bibliotherapy can be as effective as other professional modalities for certain disorders. Positive results were found in particular for the treatment of depression, anxiety, self-harm, panic disorders and relapse prevention. Researchers concluded that bibliotherapy could also form a useful adjunct to psychotherapies. More studies are needed to determine the effectiveness of bibliotherapy in treating more clinically severe illnesses (Fanner \& Urquhart, 2008).

Also, in recent years, more research has been conducted with positive results for mentally ill patients participating in bibliotherapy. In particular, reading groups that cover material regarding mental illness, videos, audiotapes, and e-material have been shown to be helpful and even key in some programs. Also, for some homebound patients bibliotherapy may be one of the few therapeutic resources at their disposal. Patients have expressed fear of going into public libraries to seek information on their illnesses because of the stigma often attached to their conditions (Fanner \& Urquhart, 2009).

The recent research and programs that have established bibliotherapy as a viable and effective treatment should encourage public, private and non-profit agencies to support this type of initiative. The difficulties could lie in the strategic planning for these libraries as well as ensuring that the materials meet the needs of the clientele, the library staff are trained to assist this clientele, and that long-term community buy-in exists for these projects (Fanner \& Urquhart, 2009).

\section{The History of Bibliotherapy}

In the early 1800's, it was not unusual for asylums to house special libraries for the purpose of educating the hospital staff, and patients together with the promotion of the hospital to relatives and benefactors. By the 1850's, doctors, and hospital-ward superintendents had begun to see bibliotherapy as an integral part of patient rehabilitation. This was during an era called the "Second Great Awakening," the beginning of social reforms such as women's rights, abolition, and a better understanding of mental illness. The terminology used at the time for the prescribed reading was "moral therapy." This type of therapy was seen as an adjunct to medical care and involved gardening, woodworking, sewing, and any other activity that would help the patient recover peacefully and with dignity (Levin, 2013).

During the early part of the 20th century, as a result of large waves of immigration and better medical diagnoses, there was an increase in patient diagnoses. Time and cost-intensive "moral therapy" began to decline. Mental hospitals became more custodial in nature rather than therapeutic (Levin, 2013). After World War II and the expansion of medical education, libraries began to serve clinicians over patients. Many clinicians claimed that bibliotherapy could not be validated as an effective means of treatment for patients. Also, certain articles were written disparaging patients as library users based on inappropriate and disruptive behavior (Fanner \& Urquhart, 2008).

Even so, some hospital librarians remained committed to bibliotherapy. One, in particular, was Sadie Peterson Delaney. She worked as the chief librarian with hospitalized black veterans in the segregated South from the 1920s until her death in the late 1950s. She defined bibliotherapy as, "the treatment of patients through selected reading." Her work with disabled and mentally ill black veterans at the U.S. Veterans Administration Hospital in Tuskegee, Alabama, included literary clubs, story hours, collecting clubs, debating, and nature studies. Through her pioneering work, Delaney received both national and international recognition (McCloskey, 1998).

\section{Bibliotherapy Research}

While the concept of bibliotherapy is not new (the Ancient Greeks coined the term which means biblio, book, and therapia, healing), definitions, concepts, and approaches differ according to who is conducting the therapy, how it is 
done and even where it is conducted (Janavenciene, 2010). However, one main principle remains clear: bibliotherapy emphasizes that discussion or counseling follows the reading of the material (McCloskey, 1998).

Some researchers divide bibliotherapy by service objective, such as clinical (which applies to medical and treatment teams), rehabilitative (adapting after a difficult illness), and educational (which refers to the identification and possible prevention of a problem). Other distinctions can include the kinds of experts who are using the process (doctors, librarians, social workers, or nurses), and the place of service (healthcare facilities, public or school libraries, social institutions, private homes) (Janavičienè, 2010).

But, whatever the scenario, many studies have shown that bibliotherapy is a sound, practical approach to mental health care.

\section{The UK Model}

Much research into the bibliotherapy model has been conducted in the UK. This is due to government policy initiatives that focus on evidence-based practices (EBP) that can be used for a countrywide plan for bibliotherapy in public libraries. Researchers and policy makers have collected information that has been of use in creating a national project (Brewster, Sen \& Cox, 2012).

\subsection{Read Yourself Well}

One such program is the Read Yourself Well initiative. This is a bibliotherapy project delivered via the public library in East Ayrshire, Scotland. This treatment plan was directed towards self-referrals and welfare agencies. One hundred and fourteen people participated in the study, which consisted of a pre-intervention and 3-month post-intervention written assessment. Changes in mental health were measured, and it was found that there was significant improvement reported at the end of the intervention period as reported by those who took part in the program (MacDonald, Vallance, \& McGrath, 2013).

\subsection{Healthy Reading}

Another example is the Healthy Reading program developed in East Lothian, Scotland. In this case, five medical practices and four public libraries partnered in 2007 to build a program that provides information, materials, and self-help techniques to those suffering from addiction, anger, anxiety, depression, eating disorders, grief, mood swings, suicide issues, and trauma due to childhood sexual assault. In this case, public librarians were given training by the local health authority responsible for the project. Health practitioners such as psychologists and counselors were sent packets that contained a list of recommended resources. Each pack contained a prescription pad that professionals could use to record their bibliotherapy "prescription," and that paper would be taken to the library to be filled. Also, a public health staffer and a local librarian held an information session that explained what was in the packet and why the materials had been selected. Promotion was through the professional mental health community and to the general public through events and leaflets (Robertson, Wray, Maxwell, \& Pratt, 2008).

A study was conducted at the end of the program that interviewed mental health professionals, consumers and librarians and overall everyone agreed that the program had been successful in providing treatment to those in distress, particularly when a patient had a long wait to see a doctor or therapist and an interim alternative was needed. Interestingly, almost all of the people interviewed agreed that the prescription notepad was helpful in reminding practitioners of this treatment and also useful in encouraging consumers to go to the library. (Robertson, Wray, Maxwell \& Pratt, 2008).

\subsection{Books on Prescription}

Another important program that began in 2003 in the UK is called Books on Prescription. This started in Cardiff, Wales. As in many countries, mental illness in the UK is on the rise. Books on Prescription was devised as a means to meet increasing frustration from consumers who lacked adequate care and access to mental health services. This program formed the basis for most of the programs that followed, including the ones in Scotland. This plan was endorsed and partially funded by the UK's National Institute for Health and Clinical Excellence. The UK government approves and supports the use of bibliotherapy as a low cost and practical intervention that when utilized through public libraries, strengthens and supports communities (Brewster, Sen \& Cox, 2012).

Books on Prescription has a somewhat inflexible model in that books are provided from a list of about 30 recommended cognitive-behavior therapy (CBT) readings. This model does not work with groups that provide discussion or support. Even so, there is a basis for its use, particularly among individuals who are good readers and are highly motivated to heal. However, this structure does not have the benefits of some of the later programs that 
use group participation to create a more flexible environment tailored to the needs of the users (Brewster, Sen, \& Cox, 2012).

\section{Bibliotherapy in the Counseling Setting}

One randomized health care study in Thailand (where depression has increased from 56 to 197 per 100,000 people between 1997 and 2007) among community health care nurses and clinicians showed that those patients who were given self-help manuals and talk follow-up showed marked improvement post-tests when compared to patients that did not participate in bibliotherapy (Songprakun \& McCann, 2012).

Another recent study sought to determine directly from counselors their use of bibliotherapy in their practice. This study concluded that overall, $79 \%$ of counselors do use bibliotherapy mainly in the form of non-fiction self-help manuals and books and that $78 \%$ saw an improvement in their patients' mental health and stability. However, it was also determined that there is little formal structure in conducting bibliotherapy, and researchers suggested that specific bibliotherapy education units be a part of a counselor's curricula. The researchers also noted that most of the books recommended and used by counselors could be freely obtained from local libraries. The researchers suggested that alliances be created so that local libraries can recommend these materials to their patrons (Pehrsson \& McMillen, 2010).

\section{Bibliotherapy in Prisons and Hospitals}

In the UK, under the auspices of the University of Liverpool and a charity called "Get Into Reading," reading groups have been formed in men's and women's prisons, mental hospitals, drug and alcohol rehabilitation units, homeless hostels, and dementia care homes. These groups focus on reading literature such as novels, short stories, and poems as a means of group therapy. In this research, there were 200 such groups (Billington, 2011).

UK prisoner mental health policies, such as "The Future Organization of Prison Healthcare" (1999) and the "National Service Framework for Mental Health" state that prisoners should receive the same level of mental health care as any others in the community. To comply with this government policy, research and published evidence of literary bibliotherapy has been collected and disseminated throughout the prison and mental health system so that best practices can be followed (Billington, 2011).

In these cases, research has shown that literary forms of bibliotherapy are superior to "self-help" reading. In one instance in which researchers sought to improve depression among patients over a 12-month period, researchers state that literature elevated the participants beyond the usual pigeon-holed treatment that dealt with their depression. Stories from Shakespeare, Thomas Hardy, Charles Dickens, and others were read and discussed. These stories provided the readers with the ability to look at themselves and their group from a more profound perspective in which concepts such as self-realization, rehabilitation and actualization could be discussed (Billington, 2011).

According to researchers, the readers become a part of an "interpretive community" that finds and creates meaning in relation to the book or poem. This dynamic is much more complex and intricate than the usual direct discussion and problem-solving techniques- Instead, participants are asked to identify and elaborate on complex experiences, which assist the participants to reflect on their lives and situations with increasing insight and awareness. Researchers and participants reported that among this group of depressed patients, calming of agitation and mental anxiety was frequently observed (Billington, 2011).

The author of this study intends to conduct further research among patients at an English women's prison in Newton, Durham, to examine the effects of literary bibliotherapy among a difficult-to-treat population that includes female prisoners engaging in self-harm. It is the hope of this researcher that English Literature and Humanities will work alongside social and biomedical sciences in the treatment of detainees and the mentally ill (Billington, 2011).

\section{Bibliotherapy for At-Risk Youth}

Bibliotherapy for young people has been a practice for many years, particularly among school librarians. One researcher describes bibliotherapy among youth as "a process that leads youth toward emotional health through the medium of literature (Jones, 2012). In today's visually stimulating environment of television, smart-phones, and computers, graphic novels have become popular among the youth as an appealing form of literature. According to research, graphic novels in grades $6-12$ can provide a means to help students with life's challenging issues (Jones, 2012). When school librarians partner with teachers and guidance counselors to provide students with materials that assist them to understand life's ups and downs, the use of literature and graphic novels becomes even more powerful. The American Association of School Librarians (AASL) provides suggestions and a list of graphic novels that will 
engage and stimulate the creativity, empathy and mental health of today's youth (http://www.ala.org/aasl/kq/v41no3).

\section{Bibliotherapy in the United States}

The recent therapeutic use of literature and the recent study of the therapeutic use of literature in the United States is limited in comparison with other countries, such as the United Kingdom. This could be because there has not been the same emphasis on public policy in the United States as there has been in the UK (Brewster, Sen, \& Cox, 2013). However, there was keen interest in the possibilities of bibliography in the mid-1970's. R. J. Rubin wrote two seminal books on the history, theory, and practice of bibliotherapy in 1978 (McCloskey, 1998).

After that time, interest and research jumps to the early 1990's, in particular dealing with using books as therapy for children and adolescents. Some researchers advocate the use of bibliotherapy with children that have ADD or have been abused. Others say that bibliotherapy should be employed using caution and have clearly defined limits and should not be substituted for traditional therapy (McCloskey, 1998).

One researcher pointed out that there are therapeutic models, certifications, and degrees within disciplines such as music therapy, art therapy, and dance therapy, but there are no best practices or certifications for bibliotherapy. This is an opportunity for literary studies or library science schools to fill a much-needed void (Pehrsson \& McMillen, 2010). All researchers conclude that while bibliotherapy may be of use to some segments of the population, more research needs to be conducted (McCloskey, 1998).

\section{Implementing a Bibliotherapy Program}

Bibliotherapy can be divided into three major practices. The first category is self-help. Nonfiction and self-help books are prescribed to the patients, and the patients are responsible for reading the material on their own. After reading, the patients check back in with their mental health advisors for feedback. Usually, the books or materials are directly related to a client's issue, such as depression. This approach is relatively low in interpersonal interaction.

The second type of bibliotherapy is creative. In this model, clients write their own fiction, drama, or poetry. This approach is more interactive, because bibliotherapists read each patient's writing and offer observation and feedback.

The last model is called informal bibliotherapy. The focus is on reading groups, recommendations from library staff or other professionals, and library displays. In the informal model, interaction between bibliotherapists and patients is dynamic. Research shows that all models are effective with the informal model showing the best results (Brewster, 2008).

Research also shows that bibliotherapy services are conducted in many settings, including medical institutions, schools, and public libraries. Also, bibliotherapy can be carried out by many types of professionals such as doctors, social workers, psychologists, teachers, and librarians (Janavičienè, 2010).

Researchers have analyzed different practices and techniques for bibliotherapy. One effective way to approach bibliotherapy is to break the process down into stages. The first stage is to identify the problem that is to be resolved using bibliotherapy. Then a professional must determine the proper text to be used. Next is reading the material. After reading the material, dialogue and interactive techniques are used to engage the reader in thoughtfully processing the material and how it applies to him or her. This stage can involve a variety of practices including one-on-one discussion with a therapist, group discussion led by a bibliotherapist, or other creative techniques such as drawing and acting. The final stage in the process is to review the reading list to ensure the materials are effective, and if not, look to other sources (Janavičienè, 2010).

Some researchers recommend formulating best practices and training for bibliotherapists. Continued research should be conducted to ensure these services are indeed effective. If these services are to be performed in a public library setting, it will be necessary to ensure that proper funding for these services is in place. Researchers see a direct correlation between bibliotherapy and the responsibility inherent in public libraries to address social and community issues. In the United Kingdom, funding is provided by a combination of public and private sources (Brewster, 2008).

\section{Analysis}

Recent research has shown the effectiveness of bibliotherapy and the vital role it can play in the lives of the mentally ill and their families. Bibliotherapy has been demonstrated to be a cost-effective treatment for clinical care and not just a recreational pursuit (Fanner \& Urquhart, 2008). 
Research indicates that it is important to identify the interests and needs of the service users. Also important is to choose materials, formats and services preferred by users. One study suggested that the most popular service was the Internet (31\%), followed by magazines (31\%) and then video (Fanner \& Urqhuart, 2009).

Also, it is imperative that staff is trained in working with mental health patients to avoid potentially uncomfortable and even frightening incidents that may arrive from miscommunication or even erroneous attitudes on behalf of the staff (Fanner \& Urqhuart, 2009).

Bibliotherapy has been shown to be most effective when utilized with the direction of a library professional rather than volunteer staff or someone not knowledgeable about library work. Also, bibliotherapy has been shown to be most helpful when all mental health service providers, including clinical staff, work together to make the program a success (Fanner \& Urqhuart, 2009).

It is important to keep abreast of new materials as they become available so that the library does not become stagnant and unappealing to users. To this end, it is vital to communicate with users as to what types of materials are of most interest to them and also to ensure that the materials are up-to-date clinically and do not provide erroneous information (Newman \& Dickens, 2012).

And finally, stable funding and institutional and community support are necessary for the success of a bibliotherapy support system. Newman and Dickens (2012) encourage buy-in from "mental health charities, co-operative relationships with public libraries, internal fundraising and suitable donations" (p. 30).

\section{Conclusions}

Severe mental illness is a worldwide crisis that is worsening. These debilitating conditions include major depression, schizophrenia, bipolar disorder, obsessive-compulsive disorder, panic disorder, post-traumatic stress disorder, and borderline personality disorder. One practical and low-cost contribution to recovery from these conditions is the use of bibliotherapy.

Bibliotherapy is the psychotherapeutic practice of giving patients and their families selected material relating to their condition with the aim of educating and alleviating these illnesses. It is an inexpensive, flexible, and efficient means of mental health care. The materials are carefully chosen books, self-help manuals, e-learning programs, and fiction or poetry. Bibliotherapy is conducted by persons instructed in the proper selection and discussion of these materials such as mental health care practitioners, teachers, or librarians. Bibliotherapy can be carried out in a multitude of settings, including health care facilities, social institutions, and libraries. There are many ways to conduct bibliotherapy, but research has shown that when the process is carried out in a group setting, the results are improved.

Several studies of applied bibliotherapy programs provide substantial, credible evidence of the efficacy of this approach. Evaluations of programs in the United Kingdom that combine the forces of government, social institutions, communities, and libraries are particularly noteworthy in this regard. Pilot programs based on the UK model should be implemented and studied, with emphasis on learning what works best in a variety of countries and communities. Based on these findings, programs should be implemented and tailored to the needs of the local population.

High costs, health care shortages and stigma have kept care from millions of people suffering from severe mental illnesses that are treatable. The government, social policies, and academic training need to gather together at this critical juncture to make bibliotherapy available to the many people in desperate need of help.

\section{Acknowledgement}

I wish to express my profound gratitude to my academic mentors Dr. Elaine Yontz and Dr. Anita Ondrusek whose support and encouragement through my years of study made this research possible. Thank you.

\section{References}

Baumeister, A., Hawkins, F., Pow, L., \& Cohen, A. (2012). Prevalence and incidence of severe mental illness in the United States: A historical view. Harvard Review Psychiatry, 287(28), 247-258.

Billington, J. (2011). Reading for Life: Prison Reading Groups in Practice and Theory. Critical Survey, 23(3), 67-85. https://doi.org/10.3167/cs.2011.230306.

Brewster, L. (2008). The Reading Remedy: Bibliotherapy in Practice. Aplis, 21(4), 172-177.

Brewster, L. (2009). Books on Prescription: Bibliotherapy in the United Kingdom. Journal of Hospital Librarianship, 9(4), 399-407. https://doi.org/10.1080/15323260903253456 
Brewster, L., Sen, B., \& Cox, A. (2012). Legitimizing Bibliotherapy: Evidence-based Discourses in Healthcare. Journal of Documentation, 68(2), 185-205. https://doi.org/10.1108/00220411211209186

Corrigan, P. W. (2005). On the stigma of mental illness: Practical strategies for research and social change, edited by Patrick W. Corrigan. Washington, DC: American Psychological Association, c2005.

Fanner, D., \& Urquhart, C. (2008). Bibliotherapy for Mental Health Service Users Part 1: A Systematic Review. Health Information and Libraries Journal, 25(4), 237-252. https://doi.org/10.1111/j.1471-1842.2008.00821.x

Fanner, D., \& Urquhart, C. (2009). Bibliotherapy for Mental Health Service Users Part 2: A Survey of Psychiatric Libraries in the UK. Health Information \& Libraries Journal, 26(2), 109-117. https://doi.org/10.1111/j.1471-1842.2008.00791

Gavigan, K. (2012). Caring through Comics - Graphic Novels and Bibliotherapy for Grades 6 - 12. Knowledge Quest, 40(5), 78-80.

Janavičienè, D. (2010). Bibliotherapy process and type analysis: Review of possibilities to use it in the library. Bridges / Tiltai, 53(4), 119-132.

Jones, J. L. (2006). A Closer Look at Bibliotherapy. Young Adult Library Services, 5(1), 24-27.

Levin, L., \& Gildea, R. (2013). Bibliotherapy: Tracing the Roots of a Moral Therapy Movement in the United States from the Early Nineteenth Century to the Present. Journal of the Medical Library Association: JMLA, 101(2), 89-91. https://doi.org/10.3163/1536-5050.101.2.003

MacDonald, J. J., Vallance, D. D., \& McGrath, M. M. (2013). An evaluation of a collaborative bibliotherapy scheme delivered via a library service. Journal of Psychiatric \& Mental Health Nursing, 20(10), 857-865. https://doi.org/10.1111/j.1365-2850.2012.01962.x

McCloskey, T. (1998). Bibliotherapy for Beginners: An Annotated Bibliography. Current Studies in Librarianship, 22(1-2), 20-33.

McMillen, P. S. (2010). A National Survey of Bibliotherapy Preparation and Practices of Professional Counselors. Journal of Creativity in Mental Health, 5(4), 412-425. https://doi.org/10.1080/15401383.2010.527807

National Alliance on Mental Illness. Mental illness facts and numbers. Retrieved from http://www.nami.org/factsheets/mentalillness_factsheet.pdf

Newman, N., \& Dickens, G. (2012). Modernizing the library service in a secure mental health setting. Mental Health Practice, 16(4), 28-32.

Reeves, W. C., Strine, T. W., Pratt, L. A., Thompson, W., Ahluwalia, I., Dhingra, S. S., ... Safran, M. A. (n.d). (2011). Mental Illness Surveillance among Adults in the United States. Morbidity and Mortality Weekly Report, 60(Suppl. S), 1-29.

Robertson, R., Wray, S. J., Maxwell, M., \& Pratt, R. J. (2008). The Introduction of a Healthy Reading Scheme for People with Mental Health Problems: Usage and Experiences of Health Professionals and Library Staff. Mental Health in Family Medicine, 5(4), 219-228.

Songprakun, W., \& Mccann, T. V. (2012). Evaluation of a Bibliotherapy Manual for Reducing Psychological Distress in People with Depression: A Randomized Controlled Trial. Journal of Advanced Nursing, 68(12), 2674-2684. https://doi.org/10.1111/j.1365-2648.2012.05966.x

Walwyn, O., \& Rowley, J. (2011). The Value of Therapeutic Reading Groups Organized by Public Libraries. Library \& Information Science Research (07408188), 33(4), 302-312. https://doi.org/10.1016/j.lisr.2011.02.005

Wig, N. (1997). Stigma against mental illness. Indian Journal of Psychiatry, 39(3), 187-189. 